\title{
Efficacy and Safety of Apatinib in Treatment of Unresectable Intrahepatic Cholangiocarcinoma: An Observational Study
}

This article was published in the following Dove Press journal: Cancer Management and Research

\author{
Yubin $\mathrm{Hu}$ (D) \\ Hailan Lin' \\ Mingzhi Hao' \\ Yan Zhou ${ }^{2}$ \\ Qizhong Chen' \\ Zhangxian Chen' \\ 'Department of Tumor Interventional \\ Radiology, Fujian Cancer Hospital \& \\ Fujian Medical University Cancer \\ Hospital, Fuzhou, Fujian Province 3500 I4, \\ People's Republic of China; ${ }^{2}$ Department \\ of Epidemiology, Fujian Cancer Hospital \\ \& Fujian Medical University Cancer \\ Hospital, Fuzhou, Fujian Province 3500I4, \\ People's Republic of China
}

Purpose: Unresectable intrahepatic cholangiocarcinoma (ICC) has a poor prognosis. The aim of this study was to evaluate the efficacy and safety of apatinib for patients with unresectable ICC.

Patients and Methods: A total of 10 patients with unresectable ICC were enrolled for this single-center observational study between March 2, 2016, and August 27, 2019. Subjects received $500 \mathrm{mg}$ apatinib on a daily basis. Tumor response was assessed by 1.1 response evaluation criteria in solid tumors. The progression-free survival (PFS) and overall survival (OS) were calculated using the Kaplan-Meier method. The drug-related adverse effects were also monitored.

Results: Based on the follow-up computed tomography and magnetic resonance imaging after treatment, 4 (40.0\%), 4 (40.0\%), and $2(20.0 \%)$ patients achieved a partial response, stable disease, and progression of the disease, respectively. The response rate and disease control rate were $40.0 \%$ and $80.0 \%$, respectively. The median PFS was 4.5 months $(95 \%$ confidence interval: 3.157 5.843 months); the median OS was 6.5 months ( $95 \%$ confidence interval: 4.744 8.256 months). Furthermore, 3-, 6-, and 9-month OS rates were 77.5\%, $61.7 \%$, and $15.0 \%$, respectively. The most common hematologic grade 3 adverse event was neutropenia (10\%); the most common nonhematologic grade 3 adverse events were hypertension $(20.0 \%)$ and hand-foot syndromes $(20.0 \%)$. No treatment-related grade 4 or 5 adverse events were recorded.

Conclusion: Apatinib revealed to have antitumour activity in unresectable ICC patients, with manageable toxicities, and thus might be used as a new treatment option for patients with unresectable ICC.

Keywords: apatinib, intrahepatic cholangiocarcinoma, targeted therapy, efficacy, safety

\section{Introduction}

Intrahepatic cholangiocarcinoma (ICC) is the second most common primary liver cancer in humans. ${ }^{1,2}$ Unlike extrahepatic bile duct cancers, ICC occurs within the hepatic parenchyma and arises from the epithelial lining of the intrahepatic biliary tract. ICC accounts for $10-20 \%$ of liver cancer and has a high mortality rate. ${ }^{3}$ Although the frequency of ICC worldwide is considerably lower than hepatocellular carcinoma (HCC), recent studies have reported an increasing number of ICC cases over the last few decades. ${ }^{4-7}$

Complete surgical resection is the only potentially curative therapy for ICC. ${ }^{5}$ However, because of its hidden features and high occurrence of lymph node
Department of Tumor Interventional Radiology, Fujian Cancer Hospital \& Fujian Medical University Cancer Hospital, No. 420 Fuma Road, Fuzhou 3500I4, Fujian Province, People's Republic of China

Tel +86-59l-62002039

Fax+86-59I-83928767

Email linhailan@fjzlhospital.com 
metastases and vascular invasion, the early diagnosis rate of ICC remains challenging. Moreover, less than $30 \%$ of patients have resectable tumors; ${ }^{2,8,9}$ the five-year survival after surgical resection of ICC is less than $45 \%$, and the recurrence is approximately $50 \% .^{8,10,11}$ Most of the patients are in the advanced stage at the time of treatment, and thus lose the opportunity for radical surgery. ${ }^{12}$ For advanced unresectable and metastatic ICC patients, the standard first-line systemic therapy of gemcitabinecisplatin has limited efficacy with an overall survival rate shorter than 1 year. ${ }^{10,13-15}$ Thus, new drugs or chemotherapeutic regimens are urgently required for patients with unresectable ICC.

Angiogenesis leads to survival, proliferation, and migration of tumor cells. ${ }^{16}$ Vascular endothelial growth factor (VEGF) is overexpressed in $53 \%$ of ICC patients, and its expression level is correlated with poor prognosis. ${ }^{17}$ Tyrosine kinase inhibitor (TKI) drugs can inhibit VEGFR and might be potentially effective targeted therapy for ICC. Clinical studies of targeted agents have attempted to improve the outcomes of the disease. However, so far, targeted agents against epidermal growth factor receptor (EGFR) and vascular endothelial growth factor receptor (VEGFR), such as sorafenib, sorafenib plus erlotinib, vandetanib and sunitinib, did not show survival benefits. ${ }^{18-21}$

Apatinib (Hengrui Pharmaceutical Co. Ltd, Shanghai, People's Republic of China) is a small-molecule TKI that selectively binds to and strongly inhibits VEGFR-2, thus inhibiting VEGF-mediated endothelial cell migration, proliferation, and microvascular tumor density. ${ }^{22}$ Apatinib was approved and accepted in 2014 by the China State Food and Drug Administration as a subsequent-line treatment for advanced or metastatic chemo-refractory gastric cancer. ${ }^{22}$ Moreover, apatinib shows a broad potential efficacy in a variety of solid tumors, including lung cancer, ovarian cancer, and advanced HCC. ${ }^{23-25}$ Nevertheless, so far, no study assessed the treatment effect of apatinib in ICC. The aim of this study was to evaluate the efficacy and safety of apatinib in patients with unresectable ICC, including those who did not respond well to first-line standard chemotherapy.

\section{Patients and Methods}

\section{Patients}

Patients with unresectable ICC were enrolled in this study. Eligibility criteria were the following: age $\geq 18$ years; histologically confirmed as ICC; at least one measurable lesion according to Response Evaluation Criteria In Solid Tumors
(RECIST) version 1.1; Eastern Cooperative Oncology Group (ECOG) performance status score less than or equal to 2; metastatic or locally advanced unresectable disease documented on diagnostic imaging studies, staging III-IV according to the American Joint Committee on Cancer (AJCC) 8th Edition Cancer Staging System; adequate hematologic function (leukocyte count $\geq 3.0 \times 10^{3} / \mu \mathrm{L}$, absolute neutrophil count at least $1.5 \times 10^{3} / \mu \mathrm{L}$, platelets $\geq 50 \times 10^{3} / \mu \mathrm{L}$, hemoglobin $>9.0 \mathrm{~g} / \mathrm{dL}$ ), liver function (total bilirubin $\leq 2 \mathrm{mg} / \mathrm{dL}$, aspartate aminotransferase and alanine aminotransferase $\leq 5$ $\times$ upper limit of reference standard) and renal function (creatinine $\leq 2 \mathrm{mg} / \mathrm{dL}$ ); chemotherapy or topical therapy (resection, radiotherapy, TACE, and RFA) should be ended 4 weeks before the study. Exclusion criteria included hepatic function Child-Pugh liver function class C; serious respiratory or cardiovascular disease; pregnant and lactating women; active infection or sepsis; other malignancies that had been diagnosed or treated before this study.

The study was reviewed and approved by the ethics committee of Fujian Cancer Hospital. All study participants, or their legal guardian, provided informed written consent prior to study enrollment. The study protocol was conducted according to the principals of the Declaration of Helsinki.

\section{Study Design and Treatments}

This was an observational study. Patients enrolled from March 2, 2016 to August 27, 2019 received apatinib $500 \mathrm{mg}$ per day, $2 \mathrm{~h}$ after a meal. When the patients encountered grade 3-4 drug-related AEs according to the Common Terminology Criteria for Adverse Events version 4.0, the drug dose was adjusted to $250 \mathrm{mg} /$ day or stopped for several days. After the adverse events were relieved, the patients were recommended to resume a daily intake of $500 \mathrm{mg} /$ day apatinib. Treatment was continued until patient's death, disease progression, drug intolerance, or withdrawal of consent from the study.

\section{Efficacy Assessment}

Overall survival (OS) was the primary trial endpoint. OS was defined as the time from treatment initiation to death. Secondary endpoints included PFS (defined as the time from treatment initiation until either disease progression or death due to any cause), objective response rate (ORR, including the rate of complete response plus partial response), disease control rate (DCR, including complete response, partial response, and stable disease) and $\mathrm{AE}$ rates. The efficacy evaluation was conducted according to the 
RECIST 1.1 criteria, including complete response (CR), partial response (PR), stable disease (SD), and progressive disease (PD). ${ }^{26}$ Tumor assessments were performed based on computed tomography and/or magnetic resonance imaging evaluation as defined by RECIST (version 1.1) at baseline and every 6-8 weeks thereafter. After disease progression, follow-up was performed every month.

\section{Statistical Analysis}

All data analyses were performed using the SPSS software (version 18.0; SPSS, Chicago, IL, USA). Median PFS and OS were calculated using the Kaplan-Meier method. Demographic data, outcome data, and other clinical parameters were presented as the frequency for categorical variables. The mean \pm standard deviation was used for continuous variables. A p-value of $<0.05$ was considered to be statistically significant.

\section{Results}

\section{Patient Characteristics of the Entire Study Group}

A total of 10 patients ( 8 males and 2 females) were enrolled in the study. Patient characteristics at baseline are summarized in Table 1. The median age of the participants was $56 \pm 7.85$ (range, 46-71) years. The mean tumor size was $6.84 \pm$ $4.41 \mathrm{~cm}$ (range: $1.7-16.9 \mathrm{~cm}$ ). Two patients were infected with hepatitis B; six patients had more than 3 tumors, and three patients had a vascular invasion. Ten patients had extrahepatic metastases, including bone $(6,60 \%)$, lung $(6,60 \%)$, regional lymph node $(10,100 \%)$ and distant lymph node (3, $30 \%)$. Four patients suffered obstructive jaundice and received percutaneous transhepatic catheterization and drainage (PTCD) before apatinib treatment. Among the 10 patients, 3 were in stage IIIB, and 7 were stage IV. Five patients $(50 \%)$ accepted local therapy before taking apatinib, including 1 chemotherapy, 1 radiotherapy, 1 TACE, and 2 resections combined chemoradiotherapy. All patients had their doses reduced, or their treatment was stopped because of the adverse events. Nine patients stopped taking apatinib because of death or disease progression, and 1 patient is still in therapy. The median duration of apatinib therapy was $4.91 \pm$ 2.11 months (range: $1.5-8.5$ months).

\section{Efficacy}

The median follow-up time was 8 months, and the mean follow-up time was $6.56 \pm 2.78$ (range: $2.0-10.3$ ) months.
Table I Baseline Clinical Characteristics of Patients

\begin{tabular}{|c|c|}
\hline Characteristics & Value \\
\hline Gender, n (\%) & \\
\hline Male & $8(80.0)$ \\
\hline Mean $\pm S D$ & $58.7 \pm 7.85$ \\
\hline Female & $2(20.0)$ \\
\hline Age (years) & \\
\hline Median & 56 \\
\hline Range & $46-71$ \\
\hline Weight & \\
\hline$\geq 60 \mathrm{~kg}$ & $5(50.0)$ \\
\hline$<60 \mathrm{~kg}$ & $5(50.0)$ \\
\hline Etiology, n (\%) & \\
\hline HBV & $3(30.0)$ \\
\hline Unknow & $7(70.0)$ \\
\hline ECOG, n (\%) & \\
\hline 1 & $7(70.0)$ \\
\hline 2 & $3(30.0)$ \\
\hline Child-Pugh class, n (\%) & \\
\hline A & $7(70.0)$ \\
\hline B & $3(30.0)$ \\
\hline Serum CAI9-9, n (\%) & \\
\hline$\geq 27 \mathrm{U} / \mathrm{mL}$ & $6(60.0)$ \\
\hline$<27 \mathrm{U} / \mathrm{mL}$ & $4(40.0)$ \\
\hline Tumor size(cm), n (\%) & \\
\hline Mean \pm SD & $6.84 \pm 4.41$ \\
\hline$\geq 5 \mathrm{~cm}$ & $7(70.0)$ \\
\hline$<5 \mathrm{~cm}$ & $3(30.0)$ \\
\hline Number of tumors, $\mathrm{n}(\%)$ & \\
\hline $1-3$ & $4(40.0)$ \\
\hline$>3$ & $6(60.0)$ \\
\hline Macroscopic vascular invasion, $\mathrm{n}(\%)$ & \\
\hline Yes & $3(30.0)$ \\
\hline No & $7(70.0)$ \\
\hline Metastatic sites, n (\%) & \\
\hline Regional lymph nodes & $10(100.0)$ \\
\hline Distant lymph nodes & $3(30.0)$ \\
\hline Lung & $6(60.0)$ \\
\hline Bone & $4(40.0)$ \\
\hline Biliary drainage & \\
\hline Yes & $2(20.0)$ \\
\hline No & $8(80.0)$ \\
\hline Previous therapy, $\mathrm{n}(\%)$ & \\
\hline No & $5(50.0)$ \\
\hline Chemotherapy & $\mathrm{I}(10.0)$ \\
\hline Radiotherapy & $\mathrm{I}(10.0)$ \\
\hline
\end{tabular}

(Continued) 
Table I (Continued).

\begin{tabular}{|l|l|}
\hline Characteristics & Value \\
\hline Resection and chemoradiotherapy & $2(20.0)$ \\
TACE & $\mathrm{I}(10.0)$ \\
\hline Disease stage, n (\%) & \\
IIIB & $3(30.0)$ \\
IV & $7(70.0)$ \\
\hline
\end{tabular}

Abbreviations: HBV, hepatitis B virus; ECOG, Eastern Cooperative Oncology Group; CA 19-9, carbohydrate antigen 19-9; TACE, transarterial chemoembolization.

Nine patients died of disease progression, which was not defined by drug-related death by investigators. Kaplan-Meier curves for PFS and OS were depicted in Figures 1 and 2, respectively. The median PFS was 4.5 (95\% CI, 3.157 5.843) months, and the median OS was 6.5 (95\% CI: $4.744 \sim 8.256$ ) months (Figure 1). The 3-month, 6-month, 9-month PFS rate was $77.5 \%, 61.7 \%$ and $15.0 \%$, respectively (Figure 2). Among 10 patients, 4 (40\%) reached PR, 4 (40\%) reached SD, and 2 (20\%) reached PD; no one reached CR. ORR and DCR were $40 \%$ and $80 \%$, respectively (Table 2 ).

\section{Safety}

No grade 4 or 5 adverse events (AEs) occurred; grade 1-3 AEs are summarized in Table 3. Generally, the treatment-related

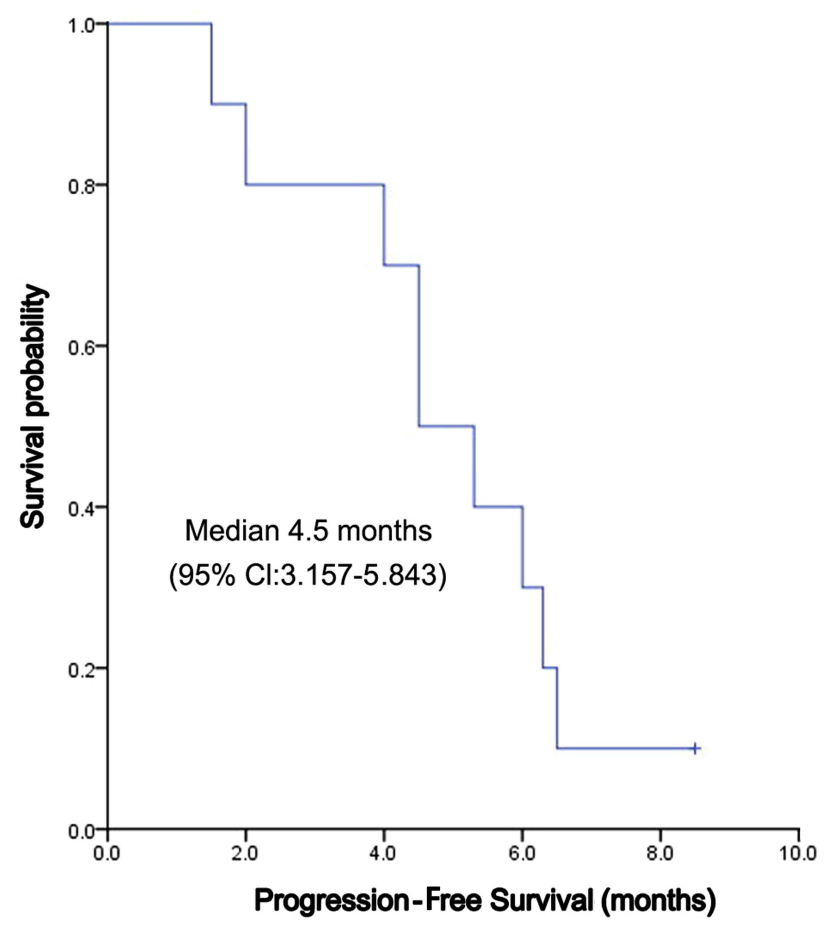

Figure I Progression-free survival of apatinib in treatment of ICC.

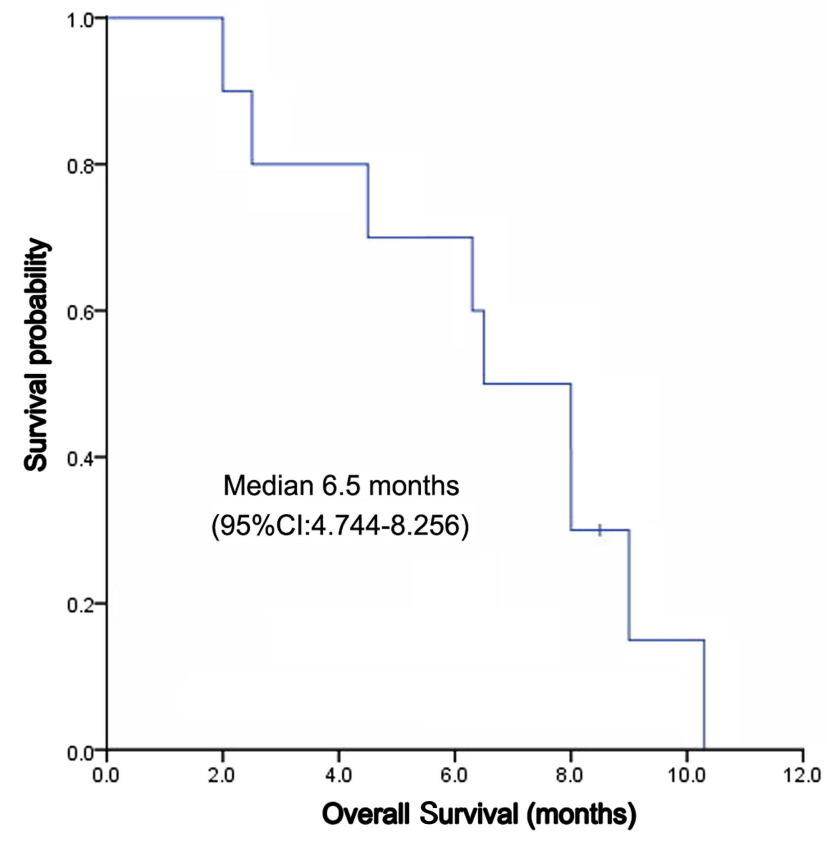

Figure 2 Overall survival of apatinib in treatment of ICC.

AEs were mild. The most common grade 3 non-hematological AEs were hypertension $(20.0 \%)$ and hand-foot syndrome (20.0\%). The most common grade 3 hematological AEs was neutropenia $(10.0 \%)$. Grade 1 hypoproteinemia $(50.0 \%)$ was the most common liver dysfunction. Grade 3 liver dysfunction was not found. Three out of the 10 patients $(30.0 \%)$ had their dose reduced to $250 \mathrm{mg} /$ day, and seven patients maintained a dose of $500 \mathrm{mg} / \mathrm{day}$. All patients could adhere to oral apatinib. No treatment-related death occurred.

\section{Discussion}

This single-arm, observational trial evaluated the efficacy and safety of apatinib treatment in patients with advanced ICC. The PFS was 4.5 months, and the OS was 6.5 months. The survival time of patients with advanced unresectable ICC who did not receive surgery, chemotherapy, or radiotherapy was

Table 2 Treatment Responses

\begin{tabular}{|l|l|}
\hline Treatment Responses & All Patients Enrolled $(\mathbf{n}=\mathbf{l 0})$ \\
\hline CR & 0 \\
PR & $4(40 \%)$ \\
SD & $4(40 \%)$ \\
PD & $2(20 \%)$ \\
ORR $(95 \% \mathrm{Cl})$ & $40 \%(26-88 \%)$ \\
DCR $(95 \% \mathrm{Cl})$ & $80 \%(44-97 \%)$ \\
\hline
\end{tabular}

Abbreviations: $C R$, complete response; $P R$, partial response; $S D$, stable disease; $P D$, progressive disease; $O R R$, objective response rate $=C R+P R / C R+P R+S D+P D$; $D C R$, disease control rate $=C R+P R+S D / C R+P R+S D+P D ; C l$, confidence interval. 
Table 3 Possible Treatment-Related Adverse Events of Apatinib in the Safety Population

\begin{tabular}{|l|l|l|l|}
\hline CTCAE Grade & I,n(\%) & II,n(\%) & III,n(\%) \\
\hline Non-haematological & & & \\
Fatigue & $4(40 \%)$ & $\mathrm{I}(10 \%)$ & $\mathrm{I}(10 \%)$ \\
Anorexia & $2(20 \%)$ & $\mathrm{I}(10 \%)$ & 0 \\
Vomiting & $\mathrm{I}(10 \%)$ & 0 & 0 \\
Diarrhea & $\mathrm{I}(10 \%)$ & 0 & 0 \\
Hoarseness & $3(30 \%)$ & 0 & 0 \\
Hypertension & $2(20 \%)$ & $4(40 \%)$ & $2(20 \%)$ \\
Hand-foot syndrome & $4(40 \%)$ & $2(20 \%)$ & $2(20 \%)$ \\
Mucositis & $3(30 \%)$ & $\mathrm{I}(10 \%)$ & 0 \\
Proteinuria & $4(40 \%)$ & $\mathrm{I}(10 \%)$ & 0 \\
Hypoproteinemia & $5(50 \%)$ & $\mathrm{I}(10 \%)$ & 0 \\
Hyperbilirubinaemia & $2(20 \%)$ & $\mathrm{I}(20 \%)$ & 0 \\
Alanine aminotransferase increased & $5(50 \%)$ & $\mathrm{I}(10 \%)$ & 0 \\
Aspartate aminotransferase increased & $4(40 \%)$ & $2(20 \%)$ & 0 \\
\hline Haematological & & & \\
Anaemia & $2(20 \%)$ & $\mathrm{I}(10 \%)$ & 0 \\
Neutropenia & $\mathrm{I}(10 \%)$ & $\mathrm{I}(10 \%)$ & $\mathrm{I}(10 \%)$ \\
Thrombocytopenia & $\mathrm{I}(10 \%)$ & $\mathrm{I}(10 \%)$ & 0 \\
\hline
\end{tabular}

Abbreviation: CTCAE, Common Terminology Criteria for Adverse Events.

3.3 months to 4.7 months if patients only received supportive therapy, including pain control, ascites control, and biliary drainage. ${ }^{27,28}$ This indicated that apatinib might be a safe and effective therapy for unresectable ICC, which was consistent with a previous small-sample retrospective study. ${ }^{29}$

Currently, systemic chemotherapy is considered the main palliative treatment for ICC; yet, its efficacy is still limited and controversial. ABC-02 study established the standard firstline chemotherapy regimen of cisplatin plus gemcitabine with OS of 11.7 months. ${ }^{13}$ Other chemotherapy regimens like nab-paclitaxel plus gemcitabine (NCT02181634) and nab-paclitaxel plus gemcitabine-cisplatin (NCT02392637) indicated an OS of 12.4 months and 19.2 months, respectively. ${ }^{14,15}$ Generally, in terms of survival time, ICC patients showed poorer prognosis compared to hilar cholangiocarcinoma patients. ${ }^{28,30}$ Patients with ECOG performance status 0 had a significantly better prognosis than patients with an ECOG 1 or ECOG 2. ${ }^{31,32}$ In ABC-02 study, $13.2 \%$ of the patients were ECOG 2; in NCT02181634 and NCT02392637 study, all of the participants were ECOG 0-1; while in this study, $30 \%$ of the patients were ECOG 2 . The patients' ECOG status in the current study was worse compared to other studies. Besides, in the present study, 50\% patients received local therapies and systemic chemotherapy before taking apatinib. Therefore, this study provided evidence for ICC patients whose ECOG status was more complicated.
Considering that toxicities of combined chemotherapeutic regimens often lead to treatment cessation, an understanding of the molecular mechanisms of ICC helps developing novel targeted therapies. ${ }^{33,34}$ Several studies on new drugs targeting different pathways have been conducted, such as dasatinib target IDH, BGJ-398 target FGFR, non-selective multi-TKIs ponatinib and pazopanib that target FGFR and MEK1/2 inhibitor selumetinib. ${ }^{35-38}$ Nevertheless, these trials are mostly small-sample Phase I/ II studies, and there is still no standard regimen of targeted drugs for ICC patients.

The toxicity profile of apatinib in this trial was similar to other molecular targeted drugs. All of the AEs were grade 1-3. There were no grade 4 or 5 AEs and no treatment-related death, which indicated tolerable toxicity of apatinib in the treatment of ICC. The incidence of hypertension, hand-foot syndrome, and proteinuria were $80 \%, 80 \%$, and $50 \%$, respectively, which was consistent with previous reports. ${ }^{22,23}$ There was no grade 3 liver dysfunction. Of haematological AEs, the most grade 3 AEs were neutropenia (10\%), while no grade $\geq 3$ anaemia or thrombocytopenia occurred, which indicated that apatinib is relatively safe. The toxicity in this trial was more tolerable than those in systemic chemotherapy. In study ABC- $02,70.7 \%$ of the patients suffered grade $\geq 3 \mathrm{AEs}, 38.4 \%$ of the patients suffered infection, and 1 patient had grade 5 renal failure. ${ }^{13}$ Moreover, in study NCT02181634, $82 \%$ of the patients suffered grade $\geq 3 \mathrm{AEs},{ }^{14}$ while in study NCT02392637, $16 \%$ of the patients withdrew from the treatment because of severe AEs. ${ }^{15}$ Also, in the current study, most AEs were controlled and reversed through dosage reduction or optimal supportive treatment. It was reported that adverse events might be predictive factors for the efficacy of apatinib, ${ }^{24}$ while for unresectable ICC patients, the understanding of adverse events and efficacy is inadequate. Considering the sample size of the present study, we did not use multivariate analysis to detect independent risk factors of efficacy.

This study has a few limitations, which include the lack of a concurrent control arm, the lack of prognostic factor analysis, the small patient population, and the selection bias caused by non-randomization. Besides, the influence of adverse events on patients' life quality was not observed. Furthermore, prospective studies are required to confirm these findings.

\section{Conclusion}

Apatinib has shown to be safe for patients with unresectable ICC. However, these findings need to be verified in a large-sample, multi-center, randomized, control trials. 


\section{Acknowledgments}

The authors would like to thank Libin Zhang, Rui Xiao and Yunbin Wang for the data acquisition. We would like to thank all of the participants in this study. Science and Technology Program of Fujian Province, China, No.2018Y2003 supported this work.

\section{Disclosure}

The authors report no conflicts of interest in this work.

\section{References}

1. Siegel RL, Miller KD, Jemal A. Cancer statistics, 2019. CA Cancer J Clin. 2019;69(1):7-34. doi:10.3322/caac.21551

2. Bridgewater J, Galle PR, Khan SA, et al. Guidelines for the diagnosis and management of intrahepatic cholangiocarcinoma. $J$ Hepatol. 2014;60(6):1268-1289. doi:10.1016/j.jhep.2014.01.021

3. Nakano M, Ariizumi SI, Yamamoto M. Intrahepatic cholangiocarcinoma. Semin Diagn Pathol. 2017;34(2):160-166. doi:10.1053/j.semdp.2016. 12.012

4. Saha SK, Zhu AX, Fuchs CS, Brooks GA. Forty-year trends in cholangiocarcinoma incidence in the U.S.: intrahepatic disease on the rise. Oncologist. 2016;21(5):594-599. doi:10.1634/theoncologist.2015-0446

5. Patel T. Increasing incidence and mortality of primary intrahepatic cholangiocarcinoma in the United States. Hepatology. 2001;33 (6):1353-1357. doi:10.1053/jhep.2001.25087

6. Massarweh NN, El-Serag HB. Epidemiology of hepatocellular carcinoma and intrahepatic cholangiocarcinoma. Cancer Control. 2017;24 (3):1073274817729245. doi:10.1177/1073274817729245

7. Chen WQ, Zheng RS, Baade PD, et al. Cancer statistics in china, 2015. CA Cancer J Clin. 2016;66(2):115-132. doi:10.3322/ caac. 21338

8. Jong MCD, Nathan H, Sotiropoulos GC, et al. Intrahepatic cholangiocarcinoma: an international multi-institutional analysis of prognostic factors and lymph node assessment. J Clin Oncol. 2011;29 (23):3140-3145. doi:10.1200/JCO.2011.35.6519

9. Tan JCC, Coburn NG, Baxter NN, Kiss A, Law CHL. Surgical management of intrahepatic cholangiocarcinoma - a population-based study. Ann Surg Oncol. 2008;15(2):600-608. doi:10.1245/s10434-007-9627-x

10. Nathan H, Pawlik TM, Wolfgang CL, Choti MA, Cameron JL, Schulick RD. Trends in survival after surgery for cholangiocarcinoma: a 30-year population-based SEER database analysis. J Gastrointest Surg. 2007;11(11):1488-1497. doi:10.1007/s11605007-0282-0

11. Ohtsuka M, Ito H, Kimura F, et al. Extended hepatic resection and outcomes in intrahepatic cholangiocarcinoma. J Hepatobiliary Pancreat Surg. 2003;10(4):259-264. doi:10.1007/s00534-002-0724-8

12. Razumilava N, Gores GJ. Cholangiocarcinoma. Lancet. 2014;383 (9935):2168-2179. doi:10.1016/S0140-6736(13)61903-0

13. Valle J, Wasan H, Palmer DH, et al. Cisplatin plus gemcitabine versus gemcitabine for biliary tract cancer. $N$ Engl J Med. 2010;362 (14):1273-1281. doi:10.1056/NEJMoa0908721

14. Sahai V, Catalano PJ, Zalupski MM, et al. Nab-paclitaxel and gemcitabine as first-line treatment of advanced or metastatic cholangiocarcinoma: a phase 2 clinical trial. JAMA Oncol. 2018;4 (12):1707-1712. doi:10.1001/jamaoncol.2018.3277

15. Shroff RT, Javle MM, Xiao LC, et al. Gemcitabine, cisplatin, and nab-paclitaxel for the treatment of advanced biliary tract cancers: a phase 2 clinical trial. JAMA Oncol. 2019;5(6):824-830. doi:10. 1001/jamaoncol.2019.0270
16. Folkman J, Parris EE, Folkman J. Tumor angiogenesis: therapeutic implication. $N$ Engl J Med. 1971;285(21):1182-1186. doi:10.1056/ NEJM197111182852108

17. Sia D, Tovar V, Moeini A, Llovet JM. Intrahepatic cholangiocarcinoma: pathogenesis and rationale for molecular therapies. Oncogene. 2013;32(41):4861-4870. doi:10.1038/onc.2012.617

18. El-Khoueiry AB, Rankin CJ, Ben-Josef E, et al. SWOG 0514: a phase II study of sorafenib in patients with unresectable or metastatic gallbladder carcinoma and cholangiocarcinoma. Invest New Drugs. 2012;30(4):1646-1651. doi:10.1007/s10637-011-9719-0

19. El-Khoueiry AB, Rankin C, Siegel AB, et al. S0941: a phase 2 SWOG study of sorafenib and erlotinib in patients with advanced gallbladder carcinoma or cholangiocarcinoma. Br J Cancer. 2014;110 (4):882-887. doi:10.1038/bjc.2013.801

20. Santoro A, Gebbia V, Pressiani T, et al. A randomized, multicenter, phase II study of vandetanib monotherapy versus vandetanib in combination with gemcitabine versus gemcitabine plus placebo in subjects with advanced biliary tract cancer: the VanGogh study. Ann Oncol. 2015;26(3):542-547. doi:10.1093/annonc/mdu576

21. Yi JH, Thongprasert S, Lee J, et al. A phase II study of sunitinib as a second-line treatment in advanced biliary tract carcinoma: a multicentre, multinational study. Eur J Cancer. 2012;48(2):196-201. doi:10.1016/j. ejca.2011.11.017

22. Li J, Qin SK, Xu JM, et al. Randomized, double-blind, placebo-controlled phase III trial of apatinib in patients with chemotherapy-refractory advanced or metastatic adenocarcinoma of the stomach or gastroesophageal junction. J Clin Oncol. 2016;34 (13):1448-1454. doi:10.1200/JCO.2015.63.5995

23. Song ZZ, Zhao LF, Zuo J, et al. Clinical outcomes and safety of apatinib mesylate in the treatment of advanced non-squamous non-small cell lung cancer in patients who progressed after standard therapy and analysis of the KDR gene polymorphism. Onco Targets Ther. 2020;13:603-613. doi:10.2147/OTT.S222985

24. Lan CY, Wang Y, Xiong Y, et al. Apatinib combined with oral etoposide in patients with platinum-resistant or platinum-refractory ovarian cancer (AEROC): a phase 2, single-arm, prospective study. Lancet Oncol. 2018;19(9):1239-1246. doi:10.1016/S1470-2045(18) 30349-8

25. Zhang YQ, Fan WZ, Wang Y, Huang GH, Li JP. Apatinib for patients with sorafenib-refractory advanced hepatitis B virus related hepatocellular carcinoma: results of a pilot study. Cancer Control. 2019;26 (1):1073274819872216. doi:10.1177/1073274819872216

26. Eisenhauer EA, Therasse P, Bogaerts J, et al. New response evaluation criteria in solid tumours: revised RECIST guideline (version 1.1). Eur J Cancer. 2009;45(2):228-247. doi:10.1016/j.ejca.2008. 10.026

27. Ji JH, Song HN, kim RB, et al. Natural history of metastatic biliary tract cancer (BTC) patients with good performance status (PS) who were treated with only best supportive care (BSC). Jpn J Clin Oncol. 2015;45(3):256-260. doi:10.1093/jjco/hyu210

28. Park SY, Kim JH, Yoon HJ, Lee IS, Yoon HK, Kim KP. Transarterial chemoembolization versus supportive therapy in the palliative treatment of unresectable intrahepatic cholangiocarcinoma. Clin Radiol. 2011;66(4):322-328. doi:10.1016/j.crad.2010.11.002

29. Liu Z, Chen JL, Fang Y, Xu FH, Pan HM, Han WD. The efficacy and safety of apatinib treatment for patients with unresectable or relapsed liver cancer: a retrospective study. J Cancer. 2018;9(16):2773-2777. doi: $10.7150 /$ jca. 26376

30. Nakeeb A, Tran KQ, Black MJ, et al. Improved survival in resected biliary malignancies. Surgery. 2002;132(4):555-564. doi:10.1067/ msy.2002.127555

31. Saxena A, Bester L, Chua TC, Chu FC, Morris DL. Yttrium-90 radiotherapy for unresectable intrahepatic cholangiocarcinoma: a preliminary assessment of this novel treatment option. Ann Surg Oncol. 2010;17(2):484-491. doi:10.1245/s10434-009-0777-x 
32. Hoffmann RT, Paprottka PM, Schön A, et al. Transarterial hepatic yttrium-90 radioembolization in patients with unresectable intrahepatic cholangiocarcinoma: factors associated with prolonged survival. Cardiovasc Intervent Radiol. 2012;35(1):105-116. doi:10.1007/ s00270-011-0142-x

33. Ma FC, Yu Q, Zeng ZM, et al. Progression-free survival of up to 8 months of an advanced intrahepatic cholangiocarcinoma patient treated with apatinib: a case report. Onco Targets Ther. 2017;10:5237-5242. doi:10.2147/OTT.S146051

34. Valle JW, Lamarca A, Goyal L, Barriuso J, Zhu AX. New horizons for precision medicine in biliary tract cancers. Cancer Discov. 2017;7 (9):943-962. doi:10.1158/2159-8290.CD-17-0245

35. Saha SK, Gordan JD, Kleinstiver BP, et al. Isocitrate dehydrogenase mutations confer dasatinib hypersensitivity and SRC dependence in intrahepatic cholangiocarcinoma. Cancer Discov. 2016;6(7):727-739. doi:10.1158/2159-8290.CD-15-1442
36. Javle M, Lowery M, Shroff RT, et al. Phase II study of BGJ398 in patients with FGFR-altered advanced cholangiocarcinoma. J Clin Oncol. 2018;36(3):276-282. doi:10.1200/JCO.2017.75.5009

37. Borad MJ, Champion MD, Egan JB, et al. Integrated genomic characterization reveals novel, therapeutically relevant drug targets in FGFR and EGFR pathways in sporadic intrahepatic cholangiocarcinoma. PLoS Genet. 2014;10(2):e1004135. doi:10.1371/journal.pgen.1004135

38. Bekaii-Saab T, Phelps MA, Li XB, et al. Multi-institutional phase II study of selumetinib in patients with metastatic biliary cancers. J Clin Oncol. 2011;29(17):2357-2363. doi:10.1200/JCO.2010.33.9473

\section{Publish your work in this journal}

Cancer Management and Research is an international, peer-reviewed open access journal focusing on cancer research and the optimal use of preventative and integrated treatment interventions to achieve improved outcomes, enhanced survival and quality of life for the cancer patient.
The manuscript management system is completely online and includes a very quick and fair peer-review system, which is all easy to use. Visit http://www.dovepress.com/testimonials.php to read real quotes from published authors. 